\title{
Phencyclidine (PCP)-Induced Disruption in Cognitive Performance is Gender-Specific and Associated with a Reduction in Brain-Derived Neurotrophic Factor (BDNF) in Specific Regions of the Female Rat Brain
}

\author{
Shikha Snigdha • Joanna C. Neill • \\ Samantha L. McLean • Gaurav K. Shemar • \\ Leonie Cruise • Mohammed Shahid • Brian Henry
}

Received: 29 April 2010 /Accepted: 3 September 2010 /Published online: 18 September 2010

(C) The Author(s) 2010. This article is published with open access at Springerlink.com

\begin{abstract}
Phencyclidine (PCP), used to mimic certain aspects of schizophrenia, induces sexually dimorphic, cognitive deficits in rats. In this study, the effects of sub-chronic PCP on expression of brain-derived neurotrophic factor (BDNF), a neurotrophic factor implicated in the pathogenesis of schizophrenia, have been evaluated in male and female rats. Male and female hooded-Lister rats received vehicle or PCP ( $n=8$ per group; $2 \mathrm{mg} / \mathrm{kg}$ i.p. twice daily for 7 days) and were tested in the attentional set shifting task prior to being sacrificed (6 weeks post-treatment). Levels of BDNF mRNA were measured in specific brain regions using in situ hybridisation. Male rats were less sensitive to PCP-induced deficits in the extra-dimensional shift stage of the attentional set shifting task compared to female rats. Quantitative analysis of brain regions demonstrated reduced BDNF levels in the medial prefrontal cortex $(p<0.05)$, motor cortex $(p<0.01)$, orbital cortex $(p<0.01)$, olfactory bulb $(p<0.05)$, retrosplenial
\end{abstract}

\footnotetext{
S. Snigdha $(\bowtie)$

Institute for Memory Impairments and Neurological Disorders, University of California, Irvine, CA 92697-4540, USA

e-mail: ssnigdha@uci.edu

J. C. Neill • S. L. McLean • G. K. Shemar

School of Pharmacy, University of Bradford, Bradford BD7 1DP, UK

L. Cruise $\cdot$ M. Shahid

Schering-Plough,

Newhouse, Scotland ML1 5SH, UK

B. Henry

Centre for Translational Medicine, Schering-Plough,

Singapore 138665, Singapore
}

cortex $(p<0.001)$, frontal cortex $(p<0.01)$, parietal cortex $(p<0.01)$, CA1 $(p<0.05)$ and polymorphic layer of dentate gyrus $(p<0.05)$ of the hippocampus and the central $(p<0.01)$, lateral $(p<0.05)$ and basolateral $(p<0.05)$ regions of the amygdaloid nucleus in female PCP-treated rats compared with controls. In contrast, BDNF was significantly reduced only in the orbital cortex and central amygdaloid region of male rats $(p<0.05)$. Results suggest that blockade of NMDA receptors by sub-chronic PCP administration has a longlasting down-regulatory effect on BDNF mRNA expression in the female rat brain which may underlie some of the behavioural deficits observed post PCP administration.

Keywords PCP. BDNF. Gender - Set-shifting $\cdot$ Rats

\section{Introduction}

Sub-chronic phencyclidine (PCP) treatment is known to produce robust cognitive and neuropathological deficits in rodents relevant to the deficits observed in schizophrenia (Abdul-Monim et al. 2006, 2007; Cochran et al. 2003; Grayson et al. 2007; Jentsch and Roth 1999; Rodefer et al. 2005; Snigdha et al. 2010; Stefani and Moghaddam 2002). Cognitive deficits in these rodent models are supported by alterations in markers for the neuronal glutamate system (Reynolds and Harte 2007). Neurotrophic factors that regulate survival and differentiation of several populations of CNS neuronal cell precursors are one of the potential effectors of such alterations and have been implicated in the pathogenesis of schizophrenia (Nawa et al. 2003; Takahashi et al. 2000; Weickert and Weinberger 1998). 
A number of reports have linked alterations in neurotrophic factors to schizophrenia (Durany et al. 2001; Guillion et al. 2007) and indeed in induction of schizophrenia-like deficits in animal models (Fumagalli et al. 2004; Lipska et al. 2001). Among the neurotrophic factors, brain-derived neurotrophic factor (BDNF) is abundantly expressed in regions involved in learning and memory of both the rat and human brain (Choi et al. 2010; Phillips et al. 1990). Moreover, at the cellular level, a diverse population of neurons have been demonstrated to be responsive to BDNF in culture. BDNF increases cell survival (Matsumoto et al. 2008) and prevents degeneration of dopaminergic and glutamatergic neurons from degeneration (Spina et al. 1992) and apoptosis, respectively (Koh et al. 1995; Xia et al. 2010). There is also direct evidence for an involvement of BDNF in learning and memory functions. BDNF antisense oligonucleotide treatment has been shown to block memory-enhancing effects in an inhibitory avoidance learning task (Ma et al. 1999). Furthermore, early-onset forebrain-restricted BDNF mutant mice are impaired in specific forms of learning as represented by the pattern discrimination and water maze tasks (Gorski et al. 2003).

Acute and sub-chronic treatment with PCP is known to induce cognitive deficits in preclinical tests such as object recognition memory, attentional set shifting and reversal learning in rats (Abdul-Monim et al. 2006; Egerton et al. 2005; Grayson et al. 2007; Idris et al. 2005; McLean et al. 2008; Rodefer et al. 2005; Snigdha et al. 2010). Furthermore, we have demonstrated male rats to be less sensitive to an acute PCP-induced deficit in recognition memory (Grayson and Neill 2004) and to have reduced cognitive capability in the novel object task compared with females (Sutcliffe et al. 2007). More recently, we have also demonstrated that PCP induces impairment in the ability of female rats to switch attention and modify their behaviour in response to changing reward contingencies in a set shifting test, following sub-chronic PCP treatment (McLean et al. 2008) an analogue of the Wisconsin Card Sorting Test in humans (Berg 1948; Birrell and Brown 2000). This test requires rats to initially learn a rule and then switch their attention to a new stimulus dimension, demonstrating cognitive flexibility.

The aim of this study was to investigate the influence of sub-chronic PCP treatment on the expression of BDNF mRNA levels in male and female rat brains using in situ hybridisation. Alternative, or additional, methodologies such as RT-PCR and northern blot analysis were also considered before undertaking the study. However, given the highly localised regional specificity of the BDNF, mRNA signal in the rat brain the likelihood of introducing a dissection artefact which may confound the data were considered too great, particularly given the objective of this study was to undertake a sub-regional analysis. Indeed, such dissection artefacts have previously been observed and reported by Pulford et al. (2006) in a study which compared alterations in mRNA levels in the choroid plexus and hippocampus of the rat using RT-PCR, microarray and in situ hybridisation. In this study, prior to killing, animals were tested in the attentional set-shifting task to confirm the incidence of a disruption in cognitive function following PCP treatment. Once confirmed, we aimed to explore the hypothesis that gender-related differences in cognition in the behavioural tests following sub-chronic PCP administration may be related to altered levels of BDNF mRNA expression in specific regions of the rat brain.

\section{Materials and Methods}

\section{Subjects}

Thirty-two hooded-Lister rats (16 adult male $270 \pm 15 \mathrm{~g}$ and 16 adult female $210 \pm 15 \mathrm{~g}$; Harlan, UK) were used in this study and were housed in groups of five (cages measured $38 \times 59 \times 24 \mathrm{~cm}$ ) under standard laboratory conditions on a 12-h light/dark cycle, lights on at 0700 hours. Temperature and humidity was maintained at $21 \pm 2^{\circ} \mathrm{C}$ and $40-50 \%$, respectively. All testing was carried out in the light phase. Rats were put on a food restriction diet 1 week prior to commencing the test $(90 \%$ of free feeding body weight), but water was available ad libitum. All experiments were conducted in accordance with the Animals Scientific Procedures Act, UK 1986 and were approved by the University of Bradford ethical review panel.

\section{Drugs and Treatment}

The rats were randomly assigned to four treatment groups; 16 (eight males and eight females) were treated with vehicle (distilled water) and 16 (eight males and eight females) with phencyclidine $(2 \mathrm{mg} / \mathrm{kg})$ twice daily for 7 days. Phencyclidine hydrochloride (PCP, Sigma, UK) or vehicle, distilled water, was administered in a volume of $1 \mathrm{ml} / \mathrm{kg}$ via the intraperitoneal route (i.p.) PCP was dissolved in distilled water. This was followed by a 7-day washout period before the rats were tested in the attentional set shifting paradigm - adapted from Birrell and Brown (2000) and described in detail by McLean et al. (2008).

\section{Tissue Processing}

Six weeks post-treatment, 24 animals (six from each treatment group) were killed by exposure to excess $\mathrm{CO}_{2}$, their brains removed, frozen in iso-pentane cooled to $-35^{\circ} \mathrm{C}$ by dry ice and stored in sealed polythene bags in a freezer at $-80^{\circ} \mathrm{C}$. 
Table 1 The effect of sub-chronic PCP ( $2 \mathrm{mg} / \mathrm{kg}$, twice daily for 7 days, i.p.) compared to vehicle on the performance, as assessed by different criteria, of male and female rats during the EDS phase of the attentional set-shifting task

\begin{tabular}{lrrrrr}
\hline Criterion: As observed in EDS phase of task & \multicolumn{2}{l}{ Males } & & \multicolumn{2}{l}{ Females } \\
\cline { 2 - 3 } \cline { 5 - 6 } & Vehicle & PCP & \multirow{2}{*}{ Vehicle } \\
\hline Average trial time(seconds) & $1.48 \pm 0.29$ & $1.47 \pm 0.09$ & $1.22 \pm 0.11$ & $1.67 \pm 0.22^{*}$ \\
Percent consecutive errors & $10.35 \pm 3.79$ & $27.5 \pm 8.70$ & $13.00 \pm 2.75$ & $30.66 \pm 6.89^{*}$ \\
Exploration of both bowls before making a choice(seconds) & $4.13 \pm 1.17$ & $3.71 \pm 0.71$ & $2.57 \pm 0.72$ & $5.38 \pm 1.20^{*}$ \\
\hline
\end{tabular}

Data are expressed as mean \pm SEM ( $n=7$ for female vehicle group, $n=8$ for female PCP group, $n=8$ for male vehicle group, $n=7$ for male PCP group) and were analysed by two-way ANOVA followed by post hoc $t$ test where a significant effect was observed

${ }^{*} p<0.05$ (significantly different from vehicle-treated group of same sex)

Serial coronal sections $(20 \mu \mathrm{m})$ from seven rostrocaudal levels were cut in a cryostat at $-15^{\circ} \mathrm{C}$ with three sections per slide mounted on nuclease-free slides (Superfrost Plus; VWR Labshop, Batavia, IL, USA). Sections were collected from Bregma coordinates 4.70 to $-2.80 \mathrm{~mm}$ in sequence of eight slides per series (Paxinos and Watson 1997). Slides of sections were stored at $-80^{\circ} \mathrm{C}$ until required for further processing. The slide-mounted sections were brought to room temperature and fixed for $10 \mathrm{~min}$ in $4 \%$ paraformaldehyde, acetylated, de-lipidised and stored at $4{ }^{\circ} \mathrm{C}$ in $95 \%$ ethanol until required for in situ hybridisation (Wisden and Morris 1994).

\section{Probe}

A 47-base antisense oligonucleotide probe was designed to target a specific sequence of rat BDNF mRNA (probe sequence: 5'-CTC CAG AGT CCC ATG GGT CCG CAC AGC TGG TAG GCC AAG TTG CCT TG-3'). Using the NCBI Basic Local Alignment Search Tool (Altschul et al.

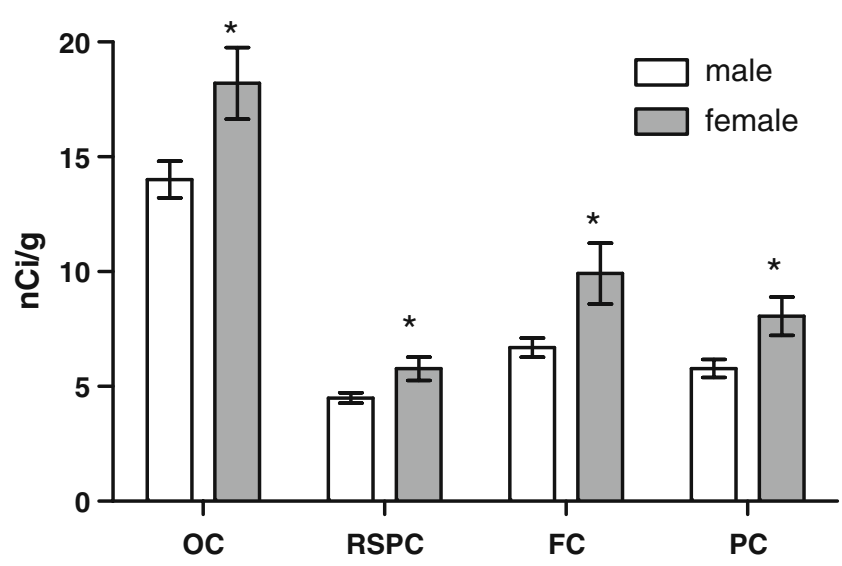

Fig. 1 BDNF mRNA levels in male and female vehicle-treated rats, female mRNA levels significantly greater than males, unpaired $t$ test $(n=5-6) * p<0.05$. $O C$ orbital cortex, $R S P C$ retrosplenial cortex, $F C$ frontal cortex, $P C$ parietal cortex
1990), the sense sequences were checked for homology with other sequences and found to be specific for the BDNF gene. Specificity of the probes for RNA was checked by hybridisation of control sections with ${ }^{33} \mathrm{P}$-labelled probes after RNase pre-treatment, which abolished all signal. To check the specificity of the probes for the desired mRNAs, control sections were incubated in hybridisation buffer containing both ${ }^{33} \mathrm{P}$-labelled and unlabelled versions of each probe, the latter at 100 -fold excess to compete with the labelled probe for specific mRNA. Competition was successful, and no signal was found in the resulting autoradiographs. Probe specificity was also checked by comparing the distribution of signal in the autoradiographs with that found in the literature. The resultant autoradiographic signal demonstrated an identical neuroanatomical distribution pattern when compared with previously published literature (Wetmore et al. 1990). The probe was 3 '-end labelled with $\left[{ }^{33} \mathrm{P}\right] \mathrm{dATP}$ and then added to 'maximalist' hybridisation buffer to give a final concentration of $0.5 \mathrm{pmol} /$ $\mathrm{ml}$ hybridisation solution as previously described (Henry et al. 1999; Sumner et al. 2004).

\section{In Situ Hybridisation}

Labelled hybridisation solution was pipetted on to each slide $(150 \mu \mathrm{l}$ per slide), which were then covered with a Hybrislip (Sigma). Sections were then hybridised for $18 \mathrm{~h}$ at $42^{\circ} \mathrm{C}$ with ${ }^{33} \mathrm{P}$-labelled oligonucleotide probes specific for BDNF mRNA. Following the incubation, the Hybrislips were floated off using $2 \times \mathrm{SSC}$ solution, and the slides were placed in racks for further processing as previously described (Henry et al 1999; Sumner et al 2004). Once dry, the sections were exposed to X-ray film (BioMax MR1 , Kodak) under 'safe' red light conditions for 14 days. An autoradiographic $\left[{ }^{14} \mathrm{C}\right]$ micro-scale (Amersham) of known radioactivity (range $31-833 \mathrm{nCi} / \mathrm{g}$ ) was also placed in each cassette to allow conversion of the optical density measurements to $\mathrm{nCi} / \mathrm{g}$. The films were then developed under 'safe' light conditions. 
Table 2 Expression of BDNF mRNA levels in male and female rats treated either with vehicle or PCP in all regions examined

All data were analysed by ANOVA followed by Bonferroni $t$ test. Underlined numbers show comparison between females (vehicle vs PCP-treated groups) and italicized numbers show comparisons between males (vehicle vs PCP-treated groups)

${ }^{*} p<0.05, \quad * * p<0.01, \quad * * * p<$ 0.001 significant decrease in mRNA levels in PCP treated males or/and females as compared with vehicle-treated males or/and females, respectively

\begin{tabular}{|c|c|c|c|c|}
\hline & \multicolumn{4}{|c|}{ Levels of BDNF mRNA (nCi/g) } \\
\hline & \multicolumn{2}{|c|}{ Vehicle- treated } & \multicolumn{2}{|l|}{ PCP-treated } \\
\hline & Male & Female & Male & Female \\
\hline MPFCortex & $12.35 \pm 2.3$ & $\underline{17.63} \pm 2.7$ & $11.83 \pm 3.1$ & $\underline{11.28 * \pm 0.9}$ \\
\hline Motor Cortex & $12.23 \pm 1.2$ & $\underline{13.97} \pm 1.1$ & $9.95 \pm 2.7$ & $\underline{9.48 * * \pm 0.8}$ \\
\hline Orbital Cortex & $14.01 \pm 1.3$ & $\underline{18.20} \pm 2.3$ & $10.58^{*} \pm 0.6$ & $\underline{13.17 * * \pm 1.2}$ \\
\hline Olfactory Bulb & $12.96 \pm 2.3$ & $\underline{17.91} \pm 2.6$ & $11.69 \pm 1.9$ & $\underline{13.00 * \pm 1.2}$ \\
\hline RSP Cortex & $4.49 \pm 0.6$ & $\underline{5.76} \pm 0.4$ & $4.11 \pm 1.1$ & $\underline{3.36 * * *} \pm 0.1$ \\
\hline Frontal Cortex & $6.68 \pm 1.3$ & $\underline{9.92} \pm 1.8$ & $4.42 \pm 2.1$ & $\underline{5.84 * *} \pm 0.6$ \\
\hline Parietal Cortex & $6.26 \pm 0.9$ & $\underline{8.05} \pm 1.3$ & $4.73 \pm 1.3$ & $\underline{5.12 * *} \pm 0.7$ \\
\hline Dentate Gyrus & $23.7 \pm 5.3$ & $24.00 \pm 5.9$ & $19.39 \pm 3.3$ & $18.72 \pm 3.7$ \\
\hline CA1 & $11.76 \pm 0.7$ & $\underline{12.48} \pm 1.2$ & $7.94 \pm 1.9$ & $\underline{7.75 * \pm 0.5}$ \\
\hline $\mathrm{CA} 2$ & $20.77 \pm 2.1$ & $20.88 \pm 6.2$ & $13.25 \pm 7.9$ & $13.30 \pm 4.9$ \\
\hline $\mathrm{CA} 3$ & $27.14 \pm 6.8$ & $26.58 \pm 4.9$ & $21.32 \pm 2.2$ & $19.12 \pm 5.2$ \\
\hline Polymorphic layer of dentate gyrus & $24.70 \pm 5.1$ & $\underline{25.44} \pm 2.3$ & $20.49 \pm 1.3$ & $\underline{18.14 * \pm 1.8}$ \\
\hline Medial Habenula & $2.78 \pm 0.8$ & $2.95 \pm 1.9$ & $2.71 \pm 1.7$ & $2.73 \pm 1.3$ \\
\hline Lateral Habenula (medial) & $2.93 \pm 1.6$ & $3.55 \pm 1.1$ & $2.587 \pm 1.9$ & $2.76 \pm 0.6$ \\
\hline Lateral Habenula (lateral) & $3.73 \pm 1.9$ & $5.00 \pm 0.8$ & $3.09 \pm 1.1$ & $3.29 \pm 2.1$ \\
\hline Paraventricular thalamic nucleus & $4.59 \pm 2.1$ & $5.02 \pm 2.3$ & $3.56 \pm 0.9$ & $3.64 \pm 0.9$ \\
\hline Dorsal Thalamus & $3.28 \pm 1.5$ & $3.48 \pm 1.6$ & $2.93 \pm 1.3$ & $2.90 \pm 1.8$ \\
\hline Ventral Thalamus & $3.72 \pm 0.9$ & $4.74 \pm 2.3$ & $3.20 \pm 1.4$ & $3.14 \pm 1.5$ \\
\hline Medial Thalamus & $3.35 \pm 0.8$ & $5.05 \pm 0.7$ & $3.37 \pm 2.1$ & $3.18 \pm 2.1$ \\
\hline Lateral Thalamus & $3.46 \pm 2.3$ & $5.17 \pm 1.4$ & $3.24 \pm 0.7$ & $2.92 \pm 1.9$ \\
\hline Central Amygdala & $6.09 \pm 1.5$ & $\underline{6.04} \pm 0.7$ & $4.41 * \pm 1.9$ & $\underline{3.66 * *} \pm 0.3$ \\
\hline Medial Amygdala & $10.16 \pm 3.3$ & $8.25 \pm 1.3$ & $7.55 \pm 1.4$ & $6.92 \pm 1.8$ \\
\hline Lateral Amygdala & $6.23 \pm 1.4$ & $\underline{6.80} \pm 0.3$ & $5.92 \pm 2.3$ & $\underline{4.82 *} \pm 0.9$ \\
\hline Basolateral Amygdala & $12.67 \pm 2.1$ & $\underline{11.54} \pm 2.4$ & $9.74 \pm 1.7$ & $6.63 * \pm 2.2$ \\
\hline
\end{tabular}

Image and Statistical Analysis

Measurements were made of 24 brain regions/subregions. Densitometric analysis of autoradiographs was performed using a Microcomputer Imaging Device (InterFocus, Ltd, Haverhill, Suffolk, UK) system. Optical density readings were converted to radioactivity values (nCi/g) by reference to the $\left[{ }^{14} \mathrm{C}\right]$-micro-scale, which enabled normalisation of data. For each region or subregion of interest, a single mean value for each brain was generated from six lateralised structures. Mean and standard error of the mean values ( $n=5-6$ per group) were then generated for each region or sub-region for each group. Results from drug- and vehicle-treated rats were compared statistically by a two-way ANOVA to detect the main effect of drug/vehicle treatment on BDNF expression in male and female rats, across different brain regions (in situ) and for different phases of the set shifting test (behaviour). This was followed by post hoc Bonferroni $t$ test if a significant effect was detected (in situ) or unpaired $t$ tests (behaviour).

\section{Results}

Effect of PCP Administration on Attentional Set Shifting Task in Female and Male Rats

Overall analysis revealed that male rats were less sensitive to PCP-induced deficits in the extra-dimensional shift (EDS) stage of the attentional set shifting task compared to female rats. An overall two-way ANOVA for the female group (EDS phase) revealed a significant effect of drug treatment on total trials to criteria, average trial time, perseverative errors and frequency exploring both bowls in the EDS phase $\left(F_{3,13}=5.3 ; p<0.01\right)$. Overall two-way ANOVA applied to male rats (EDS phase) also showed a significant main effect of treatment in these groups $\left(F_{3,13}=\right.$ $3.3 ; p<0.05)$. However, post hoc analysis showed that female, but not male, rats had a significant increase in average trial time, percentage of perseverative errors and exploration of both bowls before digging, post PCP administration compared with vehicle-treated animals $(p<0.05$; see Table 1 for summary). 
Anterior regions
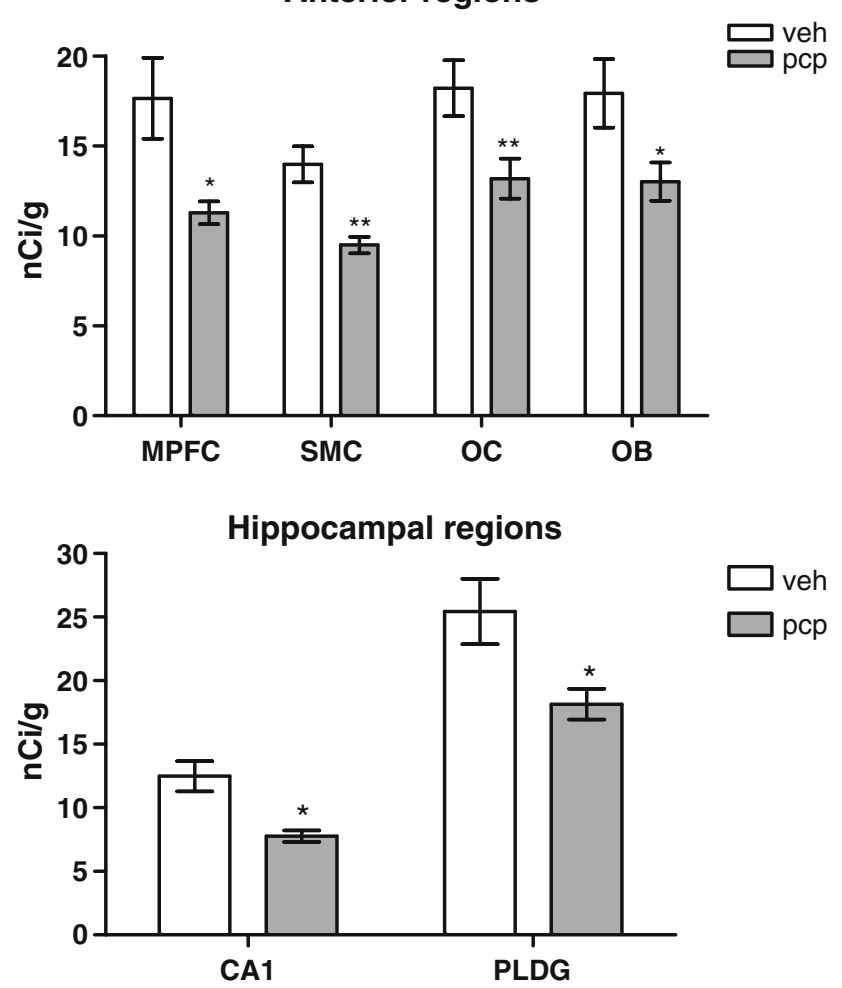

Fig. 2 The effect of subchronic PCP $(2 \mathrm{mg} / \mathrm{kg}$, i.p. twice daily for 7 days followed by 6 week drug-free) compared to vehicle on BDNF mRNA expression in female rats. Data are expressed as mean \pm SEM $(n=5-6)$ and were analysed by a two-way ANOVA followed by post hoc $t$ test. ${ }^{*} p<0.05,{ }^{* *} p<0.01, * * * p<0.001$. MPFC medial prefrontal

Sexual Dimorphism in BNDF mRNA Expression in Control (Vehicle-Treated) Rats

Unpaired $t$ tests between the vehicle male and female groups revealed significant differences between the expression of BDNF mRNA levels in the orbital $(t=2.39, p<0.05)$, retrosplenial $(t=2.30, p<0.05)$, frontal $(t=2.32, p<0.05)$ and parietal $(t=2.07, p<0.05)$ cortices in vehicle-treated animals (Fig. 1).

\section{Effect of PCP Administration on BDNF mRNA Expression} Level in Female and Male Rats

Overall two-way ANOVA (gender $\times$ drug treatment) was performed on each brain region, and where a significant effect was detected further, post hoc Bonferroni $t$ test was carried out; this showed significant decreases in BDNF mRNA expressions in the medial prefrontal cortex $(p<$ $0.05)$, motor cortex $(p<0.01)$ orbital cortex $(p<0.01)$, olfactory bulb $(p<0.05)$, retrosplenial cortex $(p<0.001)$, frontal cortex $(p<0.01)$, parietal cortex $(p<0.01), \mathrm{CA} 1(p<$ $0.05)$, polymorphic layer of dentate gyrus $(p<0.05)$ and central $(p<0.01)$, lateral $(p<0.05)$ and basolateral amygdaloid
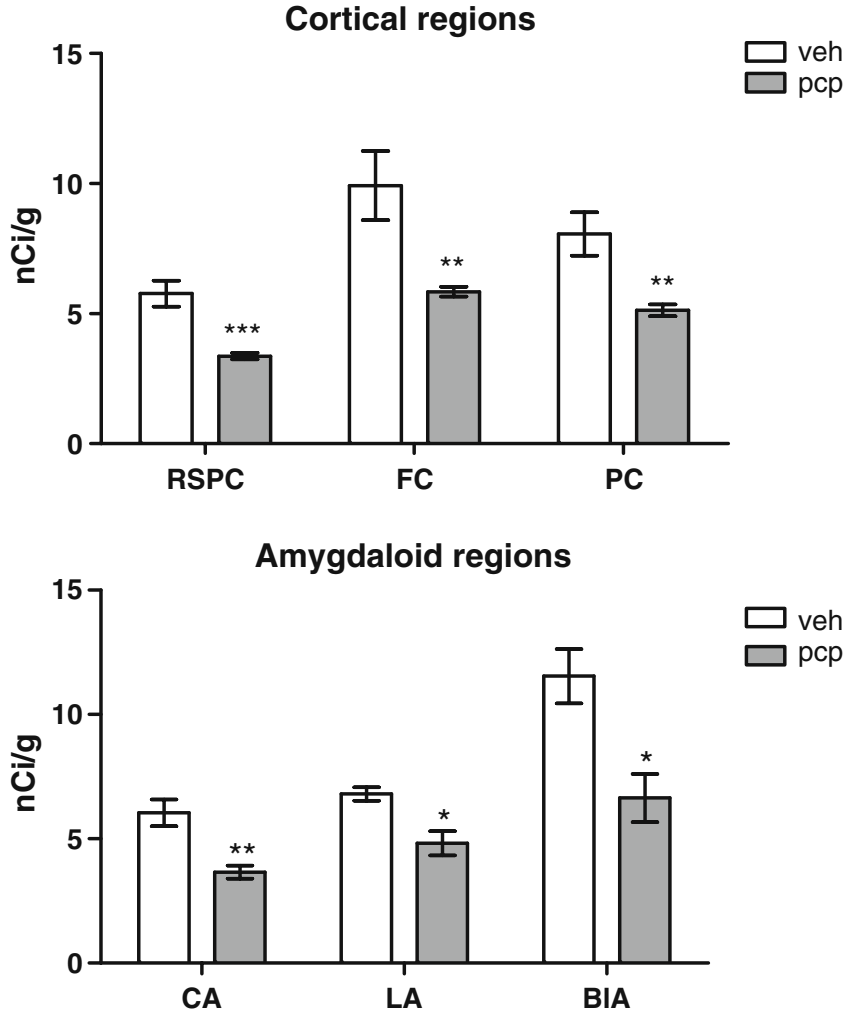

cortex, $S C$ secondary motor cortex, $O C$ orbital cortex, $O B$ olfactory nucleus, $R S P C$ retrosplenial cortex, $F C$ frontal cortex, $P C$ parietal cortex, $P L D G$ polymorphic layer of the dentate gryrus, $C A$ central amygdala, $L A$ lateral amygdala, $B l A$ basolateral amygdala

$(p<0.05)$ regions in female rats that had been treated with sub-chronic PCP 6 weeks prior to being killed compared to the vehicle treated female animals (Table 2, Figs. 2, 3a, b). In contrast, in male rats, PCP induced a reduction in BDNF only in the orbital cortex $(p<0.05)$ and central amygdaloid region $(p<0.01)$ compared with the vehicle treated male group (Fig. 4).

\section{Discussion}

The main finding of this study is that blockade of NMDA receptors by sub-chronic PCP has a down-regulatory effect on BDNF mRNA levels in the rodent brain which may relate to the behavioural deficits induced by PCP treatment. That this effect was most pronounced and widespread in female, compared with male rats, is consistent with the behavioural deficits observed in the attentional set shifting task where female rats were significantly more impaired in their ability to switch from one attentional set to another as compared to the males following sub-chronic PCP treatment (indicated by a poor performance in the EDS stage of the task, Table 1). 


\section{a}

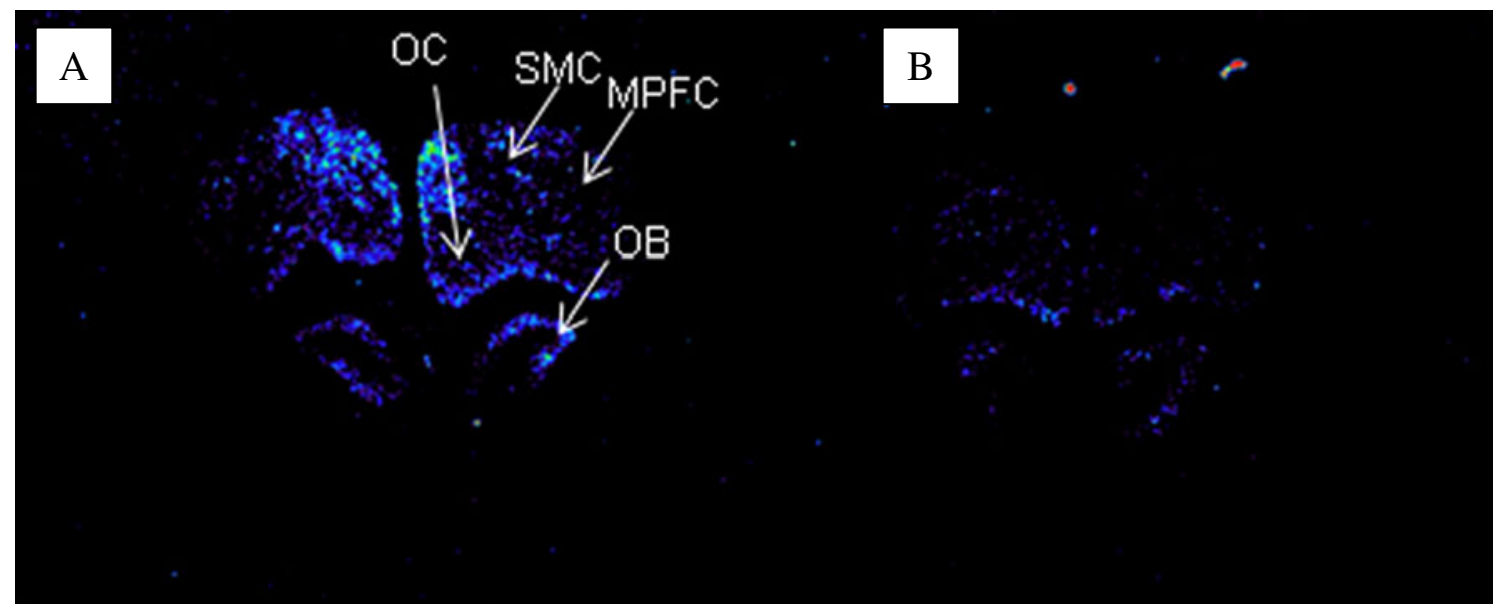

b

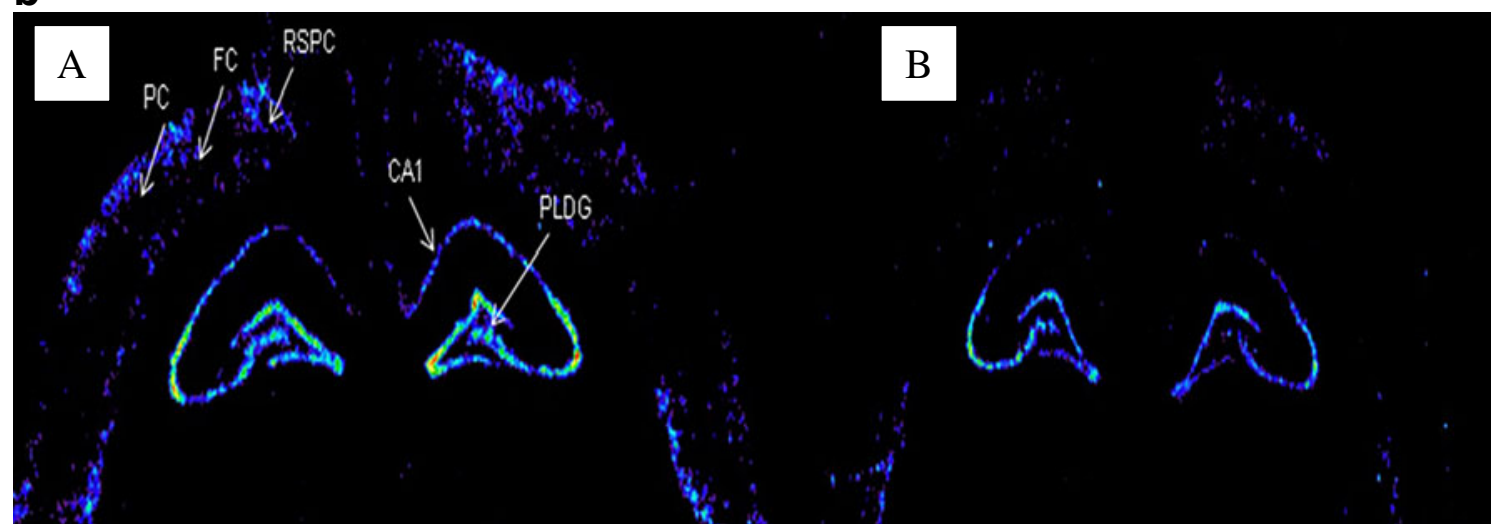

Fig. 3 a, b Representative in situ hybridisation images from the prefrontal cortex (a) and hippocampus and surrounding cortical regions(b) of the female rat brain showing effect of sub-chronic PCP on BDNF mRNA expression ( $A$ vehicle, $B$ PCP group). $O C$ orbital

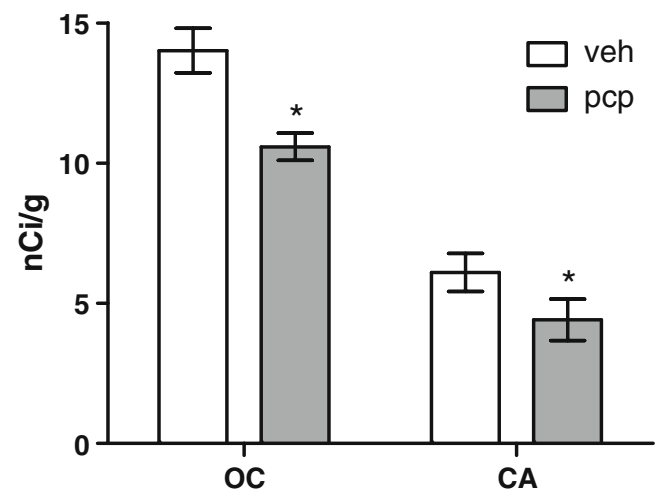

Fig. 4 The effect of subchronic PCP (2 mg/kg, i.p. twice daily for 7 days followed by 7 days drug-free) compared to vehicle on BDNF mRNA expression in male rats. Data are expressed as mean $\pm \operatorname{SEM}(n=$ 5-6) and were analysed by both repeated measures and one-way ANOVA followed by post hoc $t$ test $* p<0.05$. $O C$ orbital cortex, $C A$ central amygdala cortex, $M P F C$ medial prefrontal cortex, $S M C$ secondary motor cortex, $O B$ olfactory bulb, $R S P C$ retrosplenial cortex, $F C$ frontal cortex, $P C$ parietal cortex, $C A 1$ Cornu Ammonis area 1,PLDG polymorphic layer of the dentate gryrus

Contrasting effects of PCP treatment on BDNF levels have been reported in rats in previous studies (Hashimoto et al. 1998; Semba et al. 2006). High doses of PCP (>10 mg/ $\mathrm{kg}$, acute; $10 \mathrm{mg} / \mathrm{kg}$ sub-chronic, 14 days) have been shown to induce an increase in BDNF levels in adult male rats (Hashimoto et al. 1998; Takahashi et al. 2006). However, at this dose, PCP has been associated with neurotoxic effects in the female rat (Corso et al. 1997). This is the first study to show a significant down-regulation in BDNF mRNA following administration of sub-chronic PCP $(2 \mathrm{mg} / \mathrm{kg}$; i.p. twice daily for 7 days), a dosing regime which induces robust behavioural and hippocampal parvalbumin deficits in female rats (Abdul-Monim et al. 2007). The decrease in mRNA levels observed here was maintained for 6 weeks post-PCP-treatment. This finding is in contrast to another investigation reporting an up-regulation of BDNF protein levels in male rats using the same dosing regime as that described here (Harte et al. 2007). In the study by Harte et al., it was proposed that the up-regulation observed may be 
a compensatory response to possible neuronal damage following drug administration. While this explanation may be plausible, the mechanism by which PCP regulates BDNF expression still remains obscure. However, it has been shown that calcium plays an important role in activation of the BDNF gene (Vanhoutte and Bading 2003; West et al. 2001). It is possible that blockade of NMDA receptors by sub-chronic PCP, which has an inhibitory effect on the influx of calcium into the cells (Semba et al. 2006), may result in the reduction in BDNF mRNA expression observed in this study. An alternative explanation could be that the increases in BDNF protein levels (Harte et al. 2007) arise from regulatory feedback inhibition resulting in reductions of the mRNA expression. Nonetheless, it may be important to note that there are limitations in relating the findings of this study with those described by Harte et al (2007) as the findings described were limited to male rats and, as can be seen from our results, the sex of the animal has a significant bearing on the effect of PCP in regulating BDNF levels.

However, it is perhaps important to note that, although the present data may appear to conflict with some previous studies which report up-regulation of BDNF levels following PCP (Hashimoto et al. 1998; Takahashi et al. 2006), they are supported by data demonstrating that NMDA sub-unit mutant mice have decreased protein levels of BDNF (Takahashi et al. 2006). This is also the first study to demonstrate significant differences in the expression of BDNF in male and female rats following PCP administration. There is some evidence to show that PCP is metabolised differently in male and female rats with females having reduced ability to metabolise the drug (Shelnutt et al. 1999). This reduced ability of female rats to metabolise PCP would result in a longer compound half-life and increased exposure in female rats as compared to males, and as such, one could speculate that the difference in metabolism may underlie the difference in BDNF expression observed in this study.

Since reduced BDNF levels are likely to make neurons vulnerable to insult and even cell death (Hansen et al. 2004), it is possible that the decreased BDNF mRNA expression in the female rat brain may underlie some of the behavioural deficits as observed in the attentional set shifting task observed post PCP administration which we have observed to be more robust in female rats. Another notable finding of this study is the difference in BDNF expression in the male and female vehicle-treated animals. This finding is in agreement with previous data demonstrating increased levels of BDNF mRNA in specific regions of the cerebral cortex (Bland et al. 2005) and BDNF protein levels in the CA3 region of the hippocampus (Franklin and Perrot-Sinal 2006) of female rats in comparison to males. Moreover, in human studies, higher levels of BDNF protein in whole blood have been reported in women in comparison to men (Trajkovska et al. 2007), levels of which are altered throughout the menstrual cycle (Begliuomini et al. 2007). However, the physiological or pathological consequences of the difference in levels of BDNF in males versus female rats remain to be ascertained.

The prefrontal cortex and hippocampus have been implicated in neuropsychiatric disorders such as schizophrenia (Harrison 2004; Shenton et al. 2001). The differential effect of PCP on BDNF expression in male and female rats, together with the differences between male and female rats in the PCP-induced impairment in attentional set shifting further implicates these brain regions in cognitive dysfunction. In addition, we observe BDNF down-regulation in several cortical and amygdaloid regions, which are known to be affected in schizophrenia (Benes and Beretta 2000).

It may be advisable to interpret these results with caution and further studies exploring both specificity and temporal profile of BDNF mRNA and protein levels, correlated with behavioural deficits following PCP administration would be important in understanding the mechanism by which PCP produces a down-regulation in BDNF mRNA expression. However, the data reported in this study provide additional supportive evidence to illustrate the utility of the sub-chronic PCP-induced model of cognitive dysfunction in schizophrenia and provide insight into a potential neurobiological substrate underlying the chronic behavioural deficits observed following sub-chronic PCP exposure.

Acknowledgements SS was supported by an Organon/University of Bradford post-graduate studentship at the time of this work. GKS was a University of Bradford MSc student.

Open Access This article is distributed under the terms of the Creative Commons Attribution Noncommercial License which permits any noncommercial use, distribution, and reproduction in any medium, provided the original author(s) and source are credited.

\section{References}

Abdul-Monim Z, Reynolds GP, Neill JC (2006) The effect of atypical and classical antipsychotics on sub-chronic PCP-induced cognitive deficits in a reversal-learning paradigm. Behav Brain Res 169:263273

Abdul-Monim Z, Neill JC, Reynolds GP (2007) Sub-chronic psychotomimetic phencyclidine induces deficits in reversal learning and alterations in parvalbumin-immunoreactive expression in the rat. J Psychopharmacol 21:198-205

Altschul SF, Gish W, Miller W, Myers EW, Lipman DJ (1990) Basic local alignment search tool. J Mol Biol 215:403-410

Begliuomini S, Casarosa E, Pluchino N, Lenzi E, Centofanti M, Freschi L, Pieri M, Genazzani AD, Luisi S, Genazzani AR (2007) Influence of endogenous and exogenous sex hormones on plasma brainderived neurotrophic factor. Hum Reprod 22:995-1002

Benes FM, Beretta S (2000) Amygdalo-entorhinal inputs to the hippocampal formation in relation to schizophrenia. Ann NY Acad Sci 911:293-304 
Berg EA (1948) A simple objective treatment for measuring flexibility in thinking. J Gen Psychol 39:15-22

Birrell M, Brown VJ (2000) Medial frontal cortex mediates perceptual attentional set shifting in the rat. J Neurosci 20:4320-4324

Bland ST, Schmid MJ, Der-Avakian A, Watkins LR, Spencer RL, Maier SF (2005) Expression of c-fos and BDNF mRNA in subregions of the prefrontal cortex of male and female rats after acute uncontrollable stress. Brain Res 1051:90-99

Choi DC, Maguschak KA, Ye K, Jang SW, Myers KM, Ressler KJ (2010) Prelimbic cortical BDNF is required for memory of learned fear but not extinction or innate fear. Proc Natl Acad Sci 107:2675-2680

Cochran SM, Kennedy M, McKerchar CE, Steward LJ, Pratt JA, Morris BJ (2003) Induction of metabolic hypofunction and neurochemical deficits after chronic intermittent exposure to phencyclidine: differential modulation by antipsychotic drugs. Neuropsychopharmacology 28:265-275

Corso TD, Sesma MA, Tenkova TI, Der TC, Wozniak DF, Farber NB, Olney JW (1997) Multifocal brain damage induced by phencyclidine is augmented by pilocarpine. Brain Res 752:1-14

Durany N, Michel T, Zochling R, Boissl KW, Cruz-Sanchez FF, Riederer P, Thome J (2001) Brain-derived neurotrophic factor and neurotrophin 3 in schizophrenic psychoses. Schizophr Res 52:79-86

Egerton A, Reid L, McKerchar CE, Morris BJ, Pratt JA (2005) Impairment in perceptual attentional set-shifting following PCP administration: a rodent model of set-shifting deficits in schizophrenia. Psychopharmacology 179:77-84

Franklin TB, Perrot-Sinal TS (2006) Sex and ovarian steroids modulate brain-derived neurotrophic factor (BDNF) protein levels in rat hippocampus under stressful and non-stressful conditions. Psychoneuroendocrinology 31:38-48

Fumagalli F, Bedogni F, Perez J, Racagni G, Riva MA (2004) Corticostriatal brain-derived neurotrophic factor dysregulation in adult rats following prenatal stress. Eur J Neurosci 20:1348-1354

Gorski JA, Balogh SA et al. (2003) Learning deficits in forebrainrestricted brain-derived neurotrophic factor mutant mice. Neuroscience 121(2):341-54

Grayson B, Neill JC (2004) The effect of PCP on novel object recognition in the rat. J Psychopharmacol 18:A55

Grayson B, Idris NF, Neill JC (2007) Atypical but not classical antipsychotics attenuate a sub-chronic PCP-induced cognitive deficit in the novel object recognition task in the rat. Behav Brain Res 184:31-38

Guillion O, Demily C, Thibaut F (2007) Brain-derived neurotrophic factor in schizophrenia and its relation with dopamine. Int Rev Neurobiol 78:377-395

Hansen HH, Briem T, Dzietko M, Sifringer M, Voss A, Rzeski W, Zdzisinska B, Thor F, Heumann R, Stepulak A, Bittigau P, Ikonomidou C (2004) Mechanisms leading to disseminated apoptosis following NMDA receptor blockade in the developing rat brain. Neurobiol Dis 16:440-453

Harrison PJ (2004) The hippocampus in schizophrenia A review of the neuropathological evidence and its pathophysiological implications. Psychopharmacology (Berl) 174:151-162

Harte MK, Cahir M, Gartlon JE, Jones DN, Reynolds GP (2007) Subchronic phencyclidine administration increases brain-derived neurotrophic factor in the RAT hippocampus. Schizophr Res 94:371-372

Hashimoto K, Minabe Y, Iyo M (1998) Expression of brain-derived neurotrophic factor (BDNF) mRNA in rat retrosplenial cortex following administration of phencyclidine. Addict Biol 3:79-83

Henry B, Crossman AR, Brotchie JM (1999) Effect of repeated L-DOPA, bromocriptine, or lisuride administration on preproenkephalin- $\mathrm{A}$ and preproenkephalin-B mRNA levels in the striatum of the 6hydroxydopamine-lesioned rat. Exp Neurol 155:204-220

Idris NF, Repeto P et al. (2005) Investigation of the effects of lamotrigine and clozapine in improving reversal-learning impair- ments induced by acute phencyclidine and D-amphetamine in the rat. Psychopharmacology (Berl) 179(2):336-48

Jentsch JD, Roth RH (1999) The Neuropsychopharmacology of Phencyclidine: From NMDA Receptor Hypofunction to the Dopamine Hypothesis of Schizophrenia. Neuropsychopharmacology 20:201-225

Koh JY, Gwag BJ, Lobner D, Choi DW (1995) Potentiated necrosis of cultured cortical neurons by neurotrophins. Science 268:573-575

Lipska BK, Khaing ZZ, Weickert CS, Weinberger DR (2001) BDNF mRNA expression in rat hippocampus and prefrontal cortex: effects of neonatal ventral hippocampal damage and antipsychotic drugs. Eur J Neurosci 14:135-144

Ma YL, Chen KY, Wei CL, Lee EH (1999) Corticotropin-releasing factor enhances brain-derived neurotrophic factor gene expression to facilitate memory retention in rats. Chin J Physiol 42:73-81

Matsumoto T, Rauskolb S, Polack M, Klose J, Kolbeck R, Korte M, Barde YA (2008) Biosynthesis and processing of endogenous BDNF: CNS neurons store and secrete BDNF, not pro-BDNF. Nat Neurosci 11:131-133

McLean SL, Beck JP, Woolley ML, Neill JC (2008) A preliminary investigation into the effects of antipsychotics on sub-chronic phencyclidine-induced deficits in attentional set-shifting in female rats. Behav Brain Res 189:152-158

Nawa H, Futamura T, Mizuno M, Takahashi M, Toyooka K, Someya $\mathrm{T}$ (2003) Contribution of neurotrophic factors and cytokines to schizophrenia. Nippon Rinsho 61:521-528

Paxinos G, Watson C (1997) The rat brain in stereotaxic coordinates. Academic, New York

Phillips HS, Hains JM, Laramee GR, Rosenthal A, Winslow JW (1990) Widespread expression of BDNF but not NT3 by target areas of basal forebrain cholinergic neurons. Science 250:290-294

Pulford DJ, Adams F, Henry B, Mallinson DJ, Reid IC, Stewart CA (2006) Chronic lithium administration down regulates transthyretin mRNA expression in rat choroid plexus. Neuropsychiatr Dis Treat 2:549-555

Reynolds GP, Harte MK (2007) The neuronal pathology of schizophrenia: molecules and mechanisms. Biochem Soc Trans 35:433-436

Rodefer JS, Murphy ER, Baxter MG (2005) PDE10A inhibition reverses subchronic PCP-induced deficits in attentional set-shifting in rats. Eur J Neurosci 21:1070-1076

Semba J, Wakuta M, Suhara T (2006) Different effects of chronic phencyclidine on brain-derived neurotrophic factor in neonatal and adult rat brains. Addict Biol 11:126-130

Shelnutt SR, Gunnell M, Owens SM (1999) Sexual dimorphism in phencyclidine in vitro metabolism and pharmacokinetics in rats. $\mathrm{J}$ Pharmacol Exp Ther 290:1292-1298

Shenton ME, Dickey CC, Frumin M, McCarley RW (2001) A review of MRI findings in schizophrenia. Schizophr Res 49:1-52

Snigdha S, Horiguchi M, Li Z, Huang M, Shahid M, Neill JC, Meltzer HY (2010) Attenuation of phencyclidine-induced object recognition deficits by the combination of atypical antipsychotic drugs with pimavanserin (ACP 103), a 5-hydroxytryptamine2A receptor inverse agonist. J Pharmacol Exp Ther 332:622-631

Spina MB, Squinto SP et al. (1992) Brain-derived neurotrophic factor protects dopamine neurons against 6-hydroxydopamine and $\mathrm{N}$ methyl-4-phenylpyridinium ion toxicity: involvement of the glutathione system. J Neurochem 59(1):99-106

Stefani MR, Moghaddam B (2002) Effects of repeated treatment with amphetamine or phencyclidine on working memory in the rat. Behav Brain Res 134:267-274

Sumner BE, Cruise LA, Slattery DA, Hill DR, Shahid M, Henry B (2004) Psychopharmacology (Berlin) 171:306-321

Sutcliffe JS, Marshall KM, Neill JC (2007) Influence of gender on working and spatial memory in the novel object recognition task in the rat. Behav Brain Res 177:117-125 
Takahashi M, Shirakawa O, Toyooka K, Kitamura N, Hashimoto T, Maeda K (2000) Abnormal expression of brain-derived neurotrophic factor and its receptor in the corticolimbic system of schizophrenic patients. Mol Psychiatry 5:293-300

Takahashi M, Kakita A, Futamura T, Watanabe Y, Mizuno M, Sakimura K, Castren E, Nabeshima T, Someya T, Nawa H (2006) Sustained brain-derived neurotrophic factor up-regulation and sensorimotor gating abnormality induced by postnatal exposure to phencyclidine: comparison with adult treatment. J Neurochem 99:770-780

Trajkovska V, Marcussen AB, Vinberg M, Hartvig P, Aznar S, Knudsen GM (2007) Measurements of brain-derived neurotrophic factor: methodological aspects and demographical data. Brain Res Bull 73:143-149

Vanhoutte P, Bading H (2003) Opposing roles of synaptic and extrasynaptic NMDA receptors in neuronal calcium signalling and BDNF gene regulation. Curr Opin Neurobiol 13:366-371
Weickert CS, Weinberger DR (1998) A candidate molecule approach to defining developmental pathology in schizophrenia. Schizophr Bull 24:303-316

West AE, Chen WG, Dalva MB, Dolmetsch RE, Kornhauser JM, Shaywitz AJ, Takasu MA, Tao X, Greenberg ME (2001) Calcium regulation of neuronal gene expression. Proc Natl Acad Sci USA 98:11024-11031

Wetmore C, Ernfors P, Persson H, Olson L (1990) Localization of brain-derived neurotrophic factor mRNA to neurons in the brain by in situ hybridization. Exp Neurol 109:141-152

Wisden W, Morris BJ (eds) (1994) In situ hybridization protocols for the brain. Academic, London

Xia Y, Wang CZ, Liu J, Anastasio NC, Johnson KM (2010) Brainderived neurotrophic factor prevents phencyclidine-induced apoptosis in developing brain by parallel activation of both the ERK and PI-3 K/Akt pathways. Neuropharmacology 58:330-336 